\title{
Secondary Clinical Study Sponsor
}

National Cancer Institute

\section{Source}

National Cancer Institute. Secondary Clinical Study Sponsor. NCI Thesaurus. Code C70795.

Additional individuals, org anizations or other legal persons, if any, that have agreed with the primary sponsor to take on responsibilities of sponsorship. A secondary sponsor may have agreed -to take on all the responsibilities of sponsorship jointly with the primary sponsor; or to form a group with the primary sponsor in which the responsibilities of sponsorship are allocated among the members of the group; or to act as the sponsor's legal representative in relation to some or all of the study sites; or to take responsibility for the accuracy of study registration information submitted. 